\title{
Mikrostruktura natapianej powłoki Ni-Cr-B-Si
}

\author{
Microstructure of the Ni-Cr-B-Si \\ coating obtained in surfacing process
}

\section{Streszczenie}

Stopy Ni-Cr-B-Si są stosowane do lutowania twardego oraz do modyfikacji powierzchni w celu zwiększenia odporności na zużycie ścierne. Lutem twardym z tej grupy jest BNi-2, stosowany do łączenia stali nierdzewnych, żaroodpornych stopów niklu oraz stali stopowych. W pracy lut BNi-2 w postaci folii wykorzystano jako materiał powłokowy. Stop po natopieniu i wygrzaniu w piecu próżniowym tworzy wielofazową powłokę. Celem pracy było opisanie mikrostruktury powłoki. Wyniki badań wskazują na występowanie czterech obszarów o różnej morfologii. Wykazano obecność roztworu stałego na bazie niklu, borków niklu, borków chromu oraz krzemków niklu.

Słowa kluczowe: modyfikacja powierzchni; natapianie; stop BNi-2; powłoka wielofazowa; rentgenowska analiza fazowa
Abstract

The Ni-Cr-B-Si alloys are used for brazing and for surface modification to increase the wear resistance. The brazing alloy from this group is BNi-2, used for joining stainless steels, heat-resistant nickel alloys and alloy steels. In the work the brazing alloy BNi-2 in foil form was used as a coating material. The alloy after surfacing and soaking in a vacuum furnace forms a multiphase coating. The purpose of this work was to describe the microstructure of the coating. The results indicate on the incidence of four areas of different morphology. The presence of the solid solution based on nickel, nickel borides, chromium borides and nickel silicides was demonstrated.

Keywords: surface modification; surfacing; BNi-2 alloy; multiphase coating; X-ray diffraction analysis

\section{Wstęp}

Modyfikacja powierzchni dotyczy zamierzonej zmiany właściwości warstwy wierzchniej materiału podłoża, bądź nałożenia warstwy materiału o odmiennych właściwościach niż materiał podłoża (wytwarzanie powłok). Techniki wytwarzania warstw wierzchnich i powłok na materiałach metalowych obejmują szereg znanych i stosowanych technologii [1].

Powłoki wytwarza się na materiałach konstrukcyjnych z czterech grup ośrodków, sklasyfikowanych według ich stanu skupienia: z ośrodka stałego (np. platerowanie), z ośrodka ciekłostałego (np. natryskiwanie cieplne), z ośrodka ciekłego (np. metalizacja zanurzeniowa) oraz z ośrodka gazowego lub par (np. metody PVD i CVD) [2,3].

W praktyce przemysłowej do wytwarzania powłok na metalach stosuje się m.in. procesy pokrewne spawaniu, takie jak napawanie, natryskiwanie cieplne oraz natapianie. Dwie ostatnie techniki nie powodują stopienia materiału podłoża [4].

Stopy Ni-Cr-B-Si są stosowane do lutowania twardego stali nierdzewnych, żaroodpornych stopów niklu, stali stopowych. Znajdują zastosowanie m.in. w przemyśle lotniczym, energetycznym, chemicznym. Lutem twardym z grupy Ni-Cr-B-Si jest stop BNi-2 - oznaczenie wg American Welding Society (AWS). Innym obszarem aplikacji tych materiałów jest modyfikacja powierzchni, mająca na celu zwiększenie odporności na zużycie ścierne, odporności na działanie wysokiej temperatury, odporności na korozję [5].

W prezentowanej pracy proces modyfikacji polegał na natapianiu w piecu próżniowym stopu BNi-2 na podłoże stalowe. W wyniku natapiania i wygrzewania otrzymano wielofazową powłokę. Podstawy metody natapiania, wykorzystującej jako materiał powłokowy luty twarde, opisano w pracy [6].

\section{Cel badań}

Celem przeprowadzonych badań i analiz było opisanie mikrostruktury wielofazowej powłoki otrzymanej po natapianiu stopu BNi-2 na podłoże stalowe.

\section{Przedmiot badań}

Przedmiotem badań była powłoka powstała z natapiania i wygrzewania stopu na bazie niklu. Jako materiał powłokowy zastosowano stop BNi-2, którego skład chemiczny przedstawiono $\mathrm{w}$ tablicy I. W próbach natapiania użyto stop w postaci folii o grubości $0,05 \mathrm{~mm}$.

Jako podłoże pod powłokę zastosowano stal 42CrMo4. Skład chemiczny stali przedstawiono w tablicy II.

Mgr inż. Adam Kondej; dr hab. inż. Tomasz Babul, prof. IMP - Instytut Mechaniki Precyzyjnej. Autor korespondencyjny/Corresponding author. adam.kondej@imp.edu.pl 
Tablica I. Skład chemiczny oraz temperatury solidus i likwidus zastosowanego lutu [7]

Table I. The chemical composition, the solidus and liquidus temperature of the used brazing alloy [7]

\begin{tabular}{|c|c|c|c|c|c|c|c|}
\hline \multirow{2}{*}{ Nazwa lutu } & \multicolumn{5}{|c|}{ Zawartość pierwiastków [\% wag.] } & \multirow{2}{*}{$\begin{array}{c}\text { Temperatura } \\
\text { solid us } \\
{\left[{ }^{\circ} \mathrm{C}\right]}\end{array}$} & \multirow{2}{*}{$\begin{array}{c}\text { Temperatura } \\
\text { likwidus } \\
{\left[{ }^{\circ} \mathrm{C}\right]}\end{array}$} \\
\hline & $\mathrm{Cr}$ & $\mathrm{Fe}$ & $\mathrm{Si}$ & B & $\mathrm{Ni}$ & & \\
\hline \multirow{3}{*}{ AWS BNi-2/AMS 4777} & 7 & 3 & 4,5 & 3,2 & 82,3 & \multirow{3}{*}{971} & \multirow{3}{*}{999} \\
\hline & \multicolumn{5}{|c|}{ Zawartość pierwiastków [\% at.] } & & \\
\hline & 6,34 & 3,90 & 7,81 & 14,63 & 67,32 & & \\
\hline
\end{tabular}

Tablica II. Skład chemiczny stali 42CrMo4 - wyniki spektroskopii optycznej [6]

Table II. The chemical composition of the steel 42CrMo4 - results of optical spectroscopy [6]

\begin{tabular}{|c|c|c|c|c|c|c|c|c|c|c|c|c|}
\hline \multicolumn{10}{|c|}{ Skład chemiczny [\% wag.] } \\
\hline C & Si & $\mathrm{Mn}$ & $\mathrm{P}$ & $\mathrm{S}$ & $\mathrm{Cr}$ & $\mathrm{Mo}$ & $\mathrm{Ni}$ & $\mathrm{Al}$ & $\mathrm{Co}$ & $\mathrm{Cu}$ & $\mathrm{V}$ & $\mathrm{W}$ \\
\hline 0,42 & 0,22 & 0,61 & 0,01 & 0,005 & 1,02 & 0,16 & 0,11 & 0,01 & 0,004 & 0,16 & $<0,0011$ & $<0,01$ \\
\hline
\end{tabular}

\section{Parametry procesu}

Proces natapiania stopu BNi-2 na podłoże stalowe prowadzono w laboratoryjnym piecu próżniowym. Parametry procesu: temperatura $1075^{\circ} \mathrm{C}$, czas wygrzewania 30 minut, szybkość nagrzewania $15^{\circ} \mathrm{C} / \mathrm{min}$, ciśnienie w komorze roboczej $10^{-3}$ mbar, chłodzenie wolne - z piecem.

\section{Metodyka badań}

Badania mikrostruktury powłoki przeprowadzono na mikroskopie cyfrowym KEYENCE VHX 5000 przy powiększeniach od 250x do 1000x. Obserwacją poddano wytrawione powierzchnie poprzecznych zgładów metalograficznych powłok oraz ich powierzchnie zewnętrzne.

Do identyfikacji faz powłoki wykorzystano rentgenowską analizę fazową. Analizę przeprowadzono za pomocą dyfraktometru Rigaku MiniFlex II. Do badań użyto lampę miedzianą (głębokość wnikania promieniowania w zakresie $5 \div 7 \mu \mathrm{m}$ ), wykorzystano promieniowanie $\mathrm{K}_{\mathrm{al}}$, zakres kątowy wynosił $20 \div 100^{\circ}$.

W celu określenia rozkładu pierwiastków w powłoce wykonano mikroanalizę EDS na mikroskopie skaningowym JEOL JSM-7600F, wyposażonym w spektrometr rentgenowski z dyspersją energii X-Max INCA 250.

Pomiary twardości metodą Vickersa HV0,025 wykonano na przekrojach poprzecznych powłoki przy użyciu automatycznego twardościomierza Struers DuraScan 70.

\section{Badania mikroskopowe}

Na rysunku 1 zamieszczono obrazy mikroskopowe zgładów poprzecznych powłok o grubości około $200 \mu \mathrm{m}$ (rys. 1a)
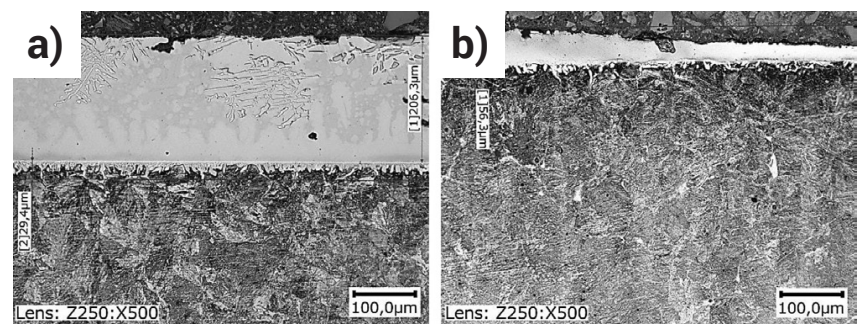

Rys. 1. Mikrostruktura powłoki powstałej po natapianiu folii BNi-2 na podłoże stalowe: a) powłoka o grubości około $200 \mu \mathrm{m}$, b) powłoka o grubości poniżej $60 \mu \mathrm{m}$

Fig. 1. Microstructure of the coating obtained in the process of surfacing of the BNi-2 foil on the steel substrate: a) coating thickness about $200 \mu \mathrm{m}, \mathrm{b})$ coating thickness of less than $60 \mu \mathrm{m}$ i grubości poniżej $60 \mu \mathrm{m}$ (rys. 1b). Na obrazach widoczna jest powłoka, strefa dyfuzji oraz podłoże stalowe.

W czasie natapiania i wygrzewania ciekły stop BNi-2 reaguje dyfuzyjnie z podłożem tworząc ziarna o nieregularnym kształcie. Podczas chłodzenia stopu formuje się wielofazowa powłoka, w której można wyróżnić cztery obszary o różnej morfologii i mikrostrukturze. W pracy [8] opisano występowanie trzech obszarów. Zmiana kontrastu podczas obserwacji na mikroskopie cyfrowym ujawniła występowanie czwartego obszaru. Na rysunku 2 oznaczono poszczególne obszary w powłoce i strefie dyfuzji.

Powłoki o różnej grubości posiadają odmienną budowę. W powłokach cienkich (rys. 1b) nie występują obszary wydzieleń dendrytycznych, udział obszarów jasno i ciemnoszarego jest ograniczony, dominuje obszar jasny.

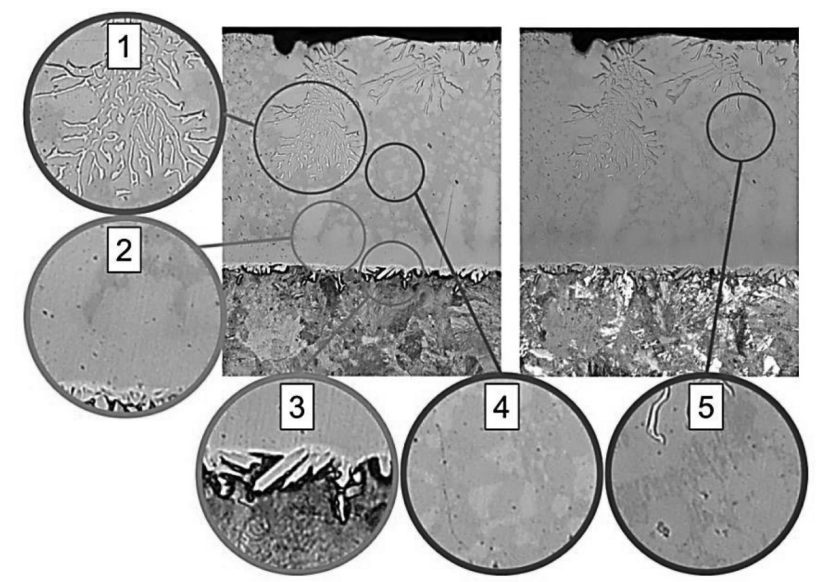

Rys. 2. Obszary występujące w powłoce i strefie dyfuzji: 1 - wydzielenia dendrytyczne, 2 - obszar jasny, 3 - ziarna w strefie dyfuzji, 4 - obszary jasnoszare, 5 - obszary ciemnoszare (widok obrazu kontrastowego)

Fig. 2. Areas in the coating and the diffusion zone: 1 - dendritic precipitates, 2 - bright areas, 3 - grains in the diffusion zone, 4 - light gray areas, 5 - dark grey areas (contrast image view)

Na rysunku 3 zamieszczono obrazy mikroskopowe powierzchni powłoki. Na rysunku 3 a widoczny jest brzeg powłoki oraz powierzchnia podłoża stalowego. Rysunek $3 \mathrm{~b}$ to obraz powierzchni powłoki na jej środku. Przedstawione obszary powłoki różnią się grubością, powłoka przy brzegu ma najmniejsza grubość. Widoczna jest różnica w budowie warstwy wierzchniej powłoki.

Na powierzchni powłoki o większej grubości widoczne są obszary mikrostruktury o nieregularnym kształcie (rys. 3b). 
Obszary te tworzy ta sama faza jak w przypadku wydzieleń dendrytycznych. Mniejsza grubość powłoki powoduje niewystępowanie tych faz zarówno na powierzchni, jak i wewnątrz powłoki. Badania twardości wskazują na wysoką twardość tych obszarów, wartości twardość mieszczą się w granicy $2000 \div 2200 \mathrm{HV} 0,025$.
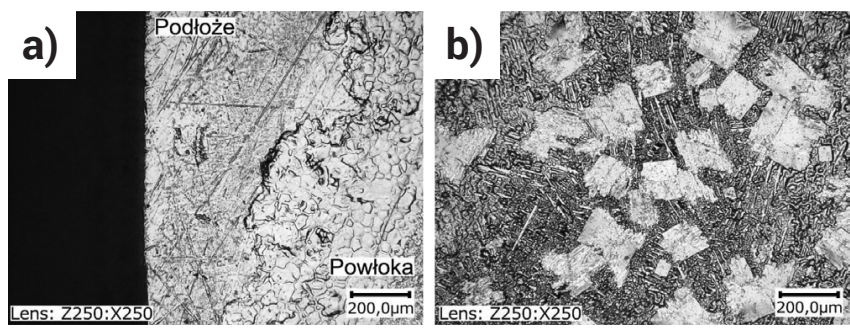

Rys. 3. Mikrostruktura powierzchni powłoki: a) przy jej brzegu, b) na środku

Fig. 3. Microstructure of the coating's surface: a) on the edge, b) in the middle

\section{Rentgenowska analiza fazowa}

Wstępny opis struktury powłoki otrzymanej z natapiania stopu BNi-2 na podłoże stalowe przestawiono w pracy [8]. W celu jednoznacznej identyfikacji obszarów powłoki, oznaczonych na rysunku 2, przeprowadzono rentgenowską analizę fazową.

$\mathrm{Na}$ rysunku 4a zamieszczono dyfraktogram z analizy powierzchni powłoki. Wyniki wskazują na obecność roztworu stałego na bazie niklu ( $\mathrm{Y}$-Ni) oraz borków niklu $\mathrm{Ni}_{2} \mathrm{~B}$.

$\mathrm{Na}$ rysunku $4 \mathrm{~b}$ zamieszczono dyfraktogram z analizy obszarów wewnątrz powłoki. Analiza fazowa wykazała obecność roztworu stałego na bazie niklu ( $\gamma-\mathrm{Ni})$, borków niklu $\mathrm{Ni}_{2} \mathrm{~B}$, a także krzemków niklu $\mathrm{Ni}_{3} \mathrm{Si}$.

a)

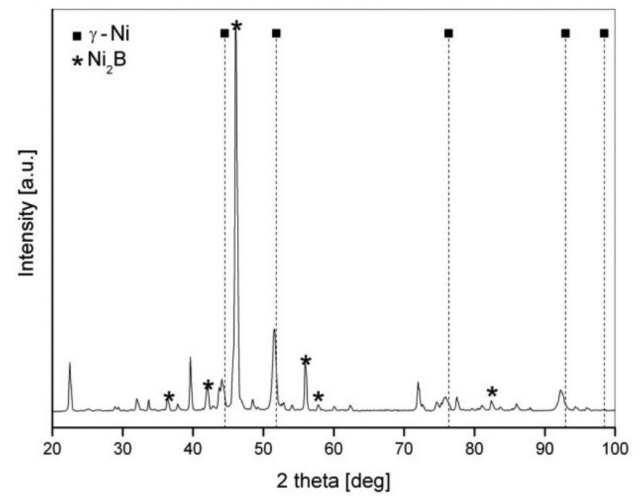

b)

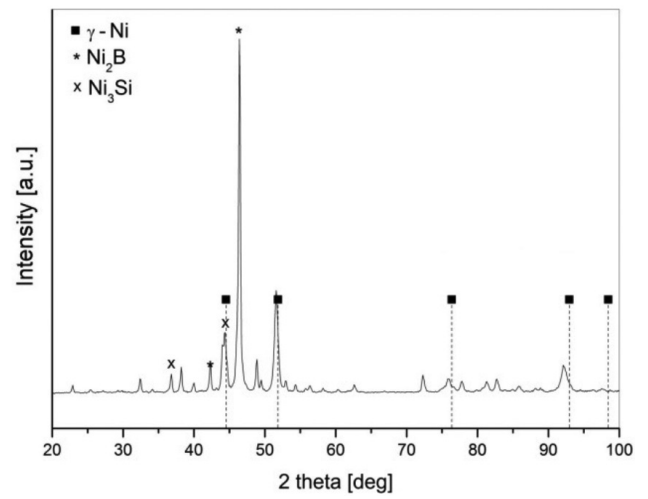

Rys. 4. Dyfraktogram dla powłoki powstałej z natapiania folii BNi-2: a) powierzchnia powłoki, b) obszary wewnątrz powłoki

Fig. 4. X-ray diffraction pattern of the coating obtained in the process of surfacing of the BNi-2 foil: a) coating's surfaces, b) areas in the coating
Wyniki prac badawczych poświęconych strukturze lutowin BNi-2 wskazują na obecność od trzech do czterech faz. W każdej potwierdzona jest obecność borków chromu CrB w obszarze wydzieleń dendrytycznych. Wyniki rentgenowskiej analizy fazowej nie ujawniły tej fazy. Na rysunku 5 przedstawiono porównanie fragmentu dyfraktogramu z rysunku $4 a$ z dyfraktogramem opublikowanym w pracy [9], w której autorzy poddali analizie fazowej komercyjny lut BNi-2. Ułożenie refleksów wskazuje na pewne podobieństwo otrzymanych wyników.

a)

b)

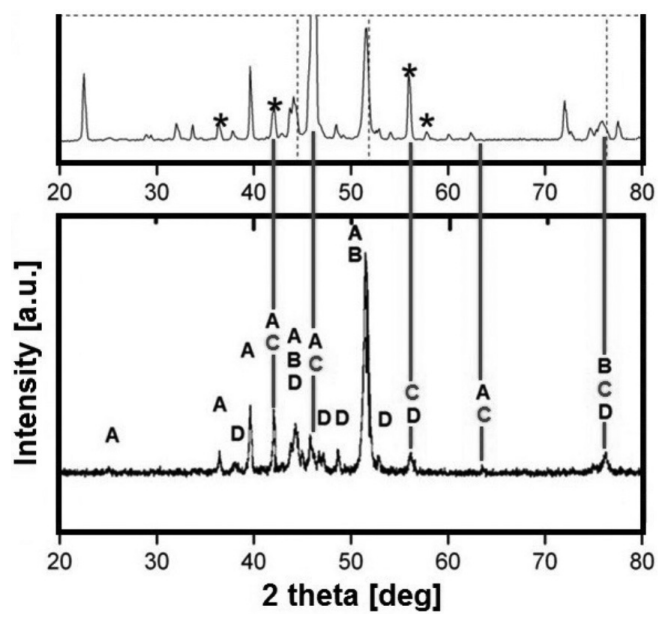

Rys. 5. Porównanie fragmentu dyfraktogramu z rysunku 4a i dyfraktogramem z pracy [9] - refleksy dyfrakcyjne zostały oznaczone jako: $\mathrm{A}-\mathrm{Ni}_{3} \mathrm{Si}, \mathrm{B}-$ roztwór stały na bazie niklu, $\mathrm{C}-\mathrm{CrB}, \mathrm{D}-\mathrm{Ni}_{3} \mathrm{~B}$

Fig. 5. Comparison of the fragment of diffraction pattern from Figure $4 a$ and the diffraction pattern from work [9] - the diffraction peaks for each phase are marked with: $A-N_{3} \mathrm{Si}, \mathrm{B}$ - nickel solid solution, $\mathrm{C}-\mathrm{CrB}, \mathrm{D}-\mathrm{Ni}_{3} \mathrm{~B}$

\section{Mikroanaliza EDS}

Analiza potrójnych wykresów równowagi fazowej Ni-Cr-B [10] wskazuje, że stop BNi-2 o składzie chemicznym przedstawionym w tabeli I, po krystalizacji będzie składał się z roztworu stałego na bazie niklu, borków niklu i borków chromu [11].

W celu określenia rozkładu pierwiastków w powłoce wykonano mikroanalizę EDS. Powierzchniowe rozkłady pierwiastków dla obszaru wydzieleń dendrytycznych zamieszczono na rysunku 6. Dane literaturowe wskazują na obecność borków chromu, czego nie wykazała jednoznacznie przeprowadzona analiza rentgenowska.

W powłoce widoczna jest segregacja pierwiastków. Obszar wydzieleń dendrytycznych jest bogaty w chrom, natomiast zubożonych w krzem, żelazo oraz nikiel. Chrom występuje w związku, na co wskazują pomiary twardości
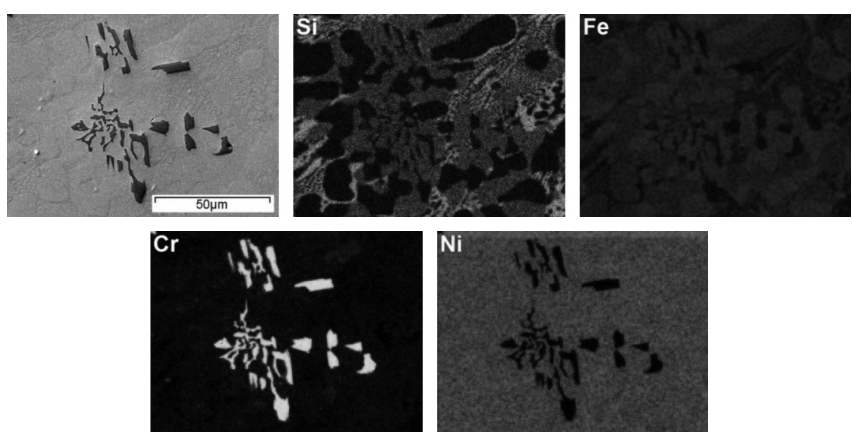

Rys. 6. Rozkład powierzchniowy pierwiastków dla obszaru wydzieleń dendrytycznych w powłoce

Fig. 6. Surface distribution of elements for the dendritic precipitates area in the coating 
- wartości twardość obszarów dendrytycznych mieszczą się w granicy $2000 \div 2200$ HV0,025. Analiza EDS nie ujawniła obecności boru ze względu na małą masę atomową. Bor wykazuje powinowactwo z chromem, tworząc m.in. borki chromu o wysokiej twardości. Najprawdopodobniej obszar wydzieleń dendrytycznych tworzą borki chromu CrB.

\section{Podsumowanie}

W wyniku natapiania i wygrzewania stopu BNi-2 powstaje wielofazowa powłoka połączona dyfuzyjnie z podłożem stalowym. W powłokach grubszych występują cztery obszary o różnej morfologii i mikrostrukturze. Za pomocą rentgenowskiej analizy fazowej, analizy wykresów równowagi fazowej, danych literaturowych, pomiarów twardości oraz wyników analizy EDS, obszary te zidentyfikowano jako: borki chromu CrB w obszarze wydzieleń dendrytycznych, krzemki niklu $\mathrm{Ni}_{3} \mathrm{Si}$ w obszarze ciemnoszarym, borki niklu $\mathrm{Ni}_{2} \mathrm{~B}$ w obszarze jasnoszarym oraz roztwór stały na bazie $\mathrm{Ni}$ ( $\mathrm{\gamma}-\mathrm{Ni})$ w obszarze jasnym.

Badania zrealizowano w Instytucie Mechaniki Precyzyjnej w ramach pracy statutowej pt. „Właściwości warstwy wierzchniej stali po selektywnej modyfikacji powierzchni z wykorzystaniem lutów na bazie Ni-Cr".

\section{Literatura}

[1] Burakowski T.: "Areologia. Podstawy teoretyczne”, Wydawnictwo Naukowe Instytutu Technologii Eksploatacji - PIB, Radom 2013.

[2] Burakowski T., Wierzchoń T.: „Inżynieria powierzchni metali - podstawy, urządzenia, technologie", Wydawnictwa Naukowo-Techniczne, Warszawa 1995

[3] Burakowski T.: „Rozważania o synergizmie w inżynierii powierzchni”, Wydawnictwo Politechniki Radomskiej, Radom 2004

[4] Ferenc K.: „Spawalnictwo", Wydawnictwa Naukowo-Techniczne, Warszawa 2013.

[5] Knotek O., Lugscheider E.: „Brazing filler metals based on reacting Ni-Cr-B-Si alloys", Welding Research Supplement, October 1976, s. 315-318.

[6] Babul T., Kondej A.: „Modyfikacja powierzchni stali przez natapianie pasty BNi-2", Przegląd Spawalnictwa, nr 4, 2015, s. 28-32.
[7] www.aimtek.com

[8] Kondej A., Babul T.: „Struktura wielofazowej powłoki otrzymanej po natapianiu pasty BNi-2 na podłoże stalowe", Inżynieria Powierzchni, nr 3, 2015, s. 10-16.

[9] Jang J.S.C., Shih H.P.: "Evolution of microstructure of AISI 304 stainless steel joint brazed by mechanically alloyed nickel base filler with different silicon content", Journal of Materials Science Letters, nr 22, 2003, s. 79-82.

[10] Villars P., Prince A., Okamoto H.: "Handbook of ternary alloy phase diagrams", ASM International, Ohio, 1995.

[11] Ou C.L., Liaw D.W., Du Y.C., Shiue R.K.: "Brazing of 422 stainless steel using the AWS classification BNi-2 braze alloy", Journal of Materials Science, nr 41, 2006, s. 6353-6361. 